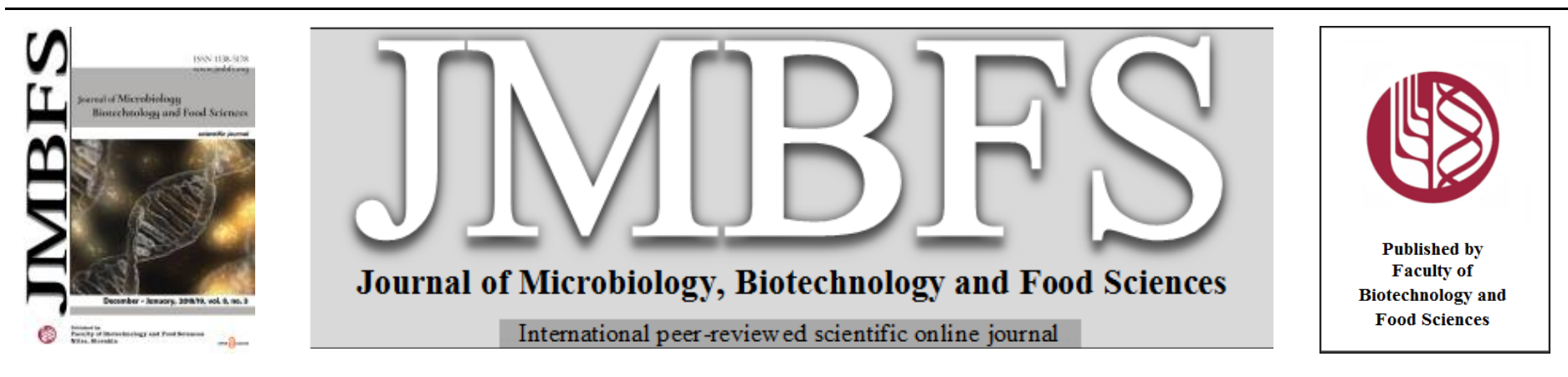

\title{
ANTIFUNGAL AND ANTIBACTERIAL ACTIVITY OF SOME LACTOBACILLI ISOLATED FROM CAMEL'S MILK BIOTOPE IN THE SOUTH OF ALGERIA
}

\author{
Senouci Djamal Eddine*, Saidi Yasmine, Ghazi Fatima, Zergui Amina, Guessas Battache and Kihal Mebrouk
}

Address(es):

Applied Microbiology Laboratory, Department of Biology, Faculty of Natural Science and Life, University Oran 1 Ahmed Ben Bella, Oran, Es-Sénia, 31100 , Algeria.

*Corresponding author: senouci.djameleddine@edu.univ-oran1.dz

doi: 10.15414/jmbfs.2018-19.8.3.871-877

\section{ARTICLE INFO}

Received 20. 3. 2018

Revised 20.9. 2018

Accepted 24. 9. 2018

Published 1. 12. 2018

Regular article OPEN $\partial_{\text {Access }}$

\begin{abstract}
Antifungal activity has been the subject of numerous recent works to fight the development of molds in food products and to reduce alteration. The objective of this study is the detection of new indigenous lactic acid bacteria (LAB) strains isolated from Algerian camel's milk which have an antifungal activity. A number of 264 LAB were isolated from fermented camel's milk where 80 rods isolates were identified by phenotypical, physiological and biochemical tests. All retained isolates belong to the genus Lactobacillus (Lb.). The antifungal activity was determined by using confrontation and overlay techniques. The screening of antifungal activity against Aspergillus niger, Aspergillus fumigatus and Penicillium sp. showed that 14 strains have an antifungal activity. These later isolates were identified as Lb. plantrarum, Lb. paracasei subsp. paracasei, Lb. brevis, Lb. rhamnosus and Lb. pentosus. These strains have shown an effect on mycelial growth and spore germination. Penicillium sp. is the most inhibited followed by Aspergillus ssp. No inhibitory activity could be detected against fungi with the supernatant. However, supernatant have an inhibitory activity against Escherichia coli, Pseudomonas aeruginosa, Staphylococcus aureus and Listeria ivanovii. P. aeruginosa is the only specie who has been affected by the neutralized supernatant. The redissolved dry supernatant of $L b$. brevis revealed an inhibition of both fungal and bacterial indicator strains. Results suggest that camel's milk LAB's strains could be selected for application to control spoilage, fungal growth and pathogenic bacteria. The use of LAB producing antifungal metabolites represents a technological advantage for the food industry.
\end{abstract}

Keywords: Antagonism, Antifungal activity, Antimicrobial, Biopreservation, Camel's milk, Lactobacillus

\section{INTRODUCTION}

Lactic acid bacteria (LAB) play an essential role in many technological processes, and especially in fermentation of food products. LAB was associated with several foods of animal or plant origin such as dairy products, meats, bakery products and also animal feed as silage. These LAB have GRAS status in the United States which means "generally recognized as safe" (Pawlowska et al., 2012). Molds are the most microorganisms implicated in the spoilage of foods and crops and causing a loss of 5 to $10 \%$ of global production (Ström, 2005). Mycotoxins are produced on a wide variety of food, before, during and after harvest. They affect many agricultural products including cereals, dried fruits, nuts, coffee beans, grapes and oilseeds. Mycotoxins are considered a part of the most significant food contaminants in terms of impact on public health, food security and the economies of some countries (Steyn, 1995; Pitt, 2000). From hundreds of mycotoxins identified at present, thirty are of significant effects in human and animal health because of their frequency or toxicity (Bennett et Klich, 2003). Chemical and physical control methods against phytopathogenic microorganisms exist, but, they are not always satisfactory. The use of chemicals such as feed additives or biocides in agriculture has increased in recent years, despite their effectiveness and preservative effect, however, they remain highly toxic and carcinogenic (Ashley-Martin et al., 2012).

$\mathrm{LAB}$ are known as agents of food preservation, this preservative effect is related to the production of various inhibitory metabolites such as organic acids, hydrogen peroxide, bacteriocins, hydroxylated, fatty acids, diacetyl and reuterin (Dalié et al., 2010; Russo et al., 2017). Currently it has become imperative to find new LAB strains, able to be used as biopreservative agents to minimize losses in food industry.

The objective of our study was the selection of bacterial strains belonging to the genus Lactobacillus isolated from Algerian camel's milk, to study their ability to inhibit the mycelial growth and conidia germination of some fungi and to show the spectrum activity of their metabolites against some bacterial strains also.

\section{MATERIAL AND METHODS}

\section{Sampling}

Camel's milk was collected from 8 sites located in the following regions in Algeria: El Abadla, Oran, Tabelbala, Adrar, Mecheria, Beni-Abbès, Timimoun and Ghardaïa. Samples were collected in sterilized bottles, kept in cool box $\left(<10^{\circ} \mathrm{C}\right)$ containing ice packs during the transport to laboratory and processed within 2 days. The milk samples were incubated for $48 \mathrm{~h}$ at $30^{\circ} \mathrm{C}$ until the milk being coagulated. This incubation stimulates the growth of LAB present in raw milk.

\section{Isolation of lactic acid bacteria}

For the isolation of LAB, successive decimal dilutions were performed in sterile physiological water to the order of $10^{-7}$. A volume of $1 \mathrm{ml}$ was taken from the dilution $10^{-5}, 10^{-6}$ and inoculated in selective MRS medium supplemented with $\mathrm{CaCO}_{3}(5 \mathrm{~g} / \mathrm{l})$ (Sigma-Aldrich, Germany) to reveal production of lactic acid by a clear zone around the colonies and $0.01 \%$ cycloheximide (Sigma-Aldrich, Germany) to inhibit yeast and fungal growth. Cultures were incubated anaerobically at $30^{\circ} \mathrm{C}$ for $72 \mathrm{~h}$. After incubation, ten (10) representative and typical colonies of LAB (shape, size, pigmentation, outline, viscosity) were randomly chosen.

\section{Purification of isolates}

The selected colonies were then sub-cultured in MRS broth and incubated at $30^{\circ} \mathrm{C}$. After incubation, the strains that have developed were inoculated successively on MRS medium supplemented with $0.01 \%$ of cycloheximide. Isolates have been examined for the Gram stain and catalase reaction. Gram positive and catalase negative isolates were presumed as LAB. The strains of LAB were stored in skimmed milk with $30 \%(\mathrm{v} / \mathrm{v})$ glycerol (Biolife, Italy) at $20^{\circ} \mathrm{C}$. 


\section{LAB identification}

Temperature growth was assessed by the presence of an unclear MRS broth culture after $72 \mathrm{~h}$ of incubation at 15,37 and $45^{\circ} \mathrm{C}$. The fermentation type was determined by gas production from glucose in MRS broth, containing inverted Durham tube. To determine the fermentation type, sodium-gluconate-MRS broth was used. Presence of arginine dihydrolase (ADH) was tested on M16-BCP medium. LAB which metabolizes lactose, produce lactic acid and acidify the medium then give a yellow coloration around the colonies. While for those were able to use arginine, the release of $\mathrm{NH}_{4}$ re-alkalize the medium then colonies appear white (Thomas, 1973; Mathot et $\boldsymbol{a l . , 1 9 9 4 ) .}$

\section{Carbohydrates Fermentation profile}

The carbohydrates API 50 CHL test kit (bioMérieux, France) were used to tes the ability of isolates to ferment 49 carbohydrates. A fresh culture (18-24 h) in MRS broth was centrifuged and washed with physiological water. The cells were introduced into API CHL medium. These samples were then tested with the API strips according to the manufacturer's instructions, cupules were covered with paraffin oil, and the results were read after $24 \mathrm{~h}$ and $48 \mathrm{~h}$ of incubation at $30^{\circ} \mathrm{C}$. The species identification was established with apiweb ${ }^{\text {TM }}$ V5.2 (bioMérieux).

\section{Origin of fungal and bacterial strains}

Aspergillus niger was procured from parasitology and mycology laboratory of Sidi Bel Abbes hospital. The strain Penicillium sp. obtained from Mascara hospital and Aspergillus fumigatus MNHN566 from the National Museum of Natural History, France. The bacterial strains, Escherichia coli ATCC 25922, Staphylococcus aureus ATCC 25923, were offered by the central laboratory of Oran hospital. Listeria ivanovii ATCC 19119 comes from the collection of Applied Microbiology Laboratory Oran 1 University. Pseudomonas aeruginosa is belonging to the collection of Environmental Surveillance Network Laboratory Oran 1 University.

\section{Fungal growth conditions}

The three strains A. niger, A. fumigatus and Penicillium. sp were grown on potato dextrose agar (PDA) medium at $30^{\circ} \mathrm{C}$ for 7 days and then $10 \mathrm{ml}$ of sterile distilled water were put to get monospore suspension. The suspension obtained was filtered through Whatman paper $(180 \mu \mathrm{m})$. The conidia were counted using a Malassez cell (Belkacem-Hanfi et al., 2014).

\section{Antifungal activity screening}

Confrontation method is a qualitative test which aims to demonstrate the antifungal activity of the isolated bacteria. Strains were first inoculated in two parallel $2 \mathrm{~cm}$ stripes on MRS medium (without sodium acetate), and then incubated anaerobically at $30^{\circ} \mathrm{C}$ for $48 \mathrm{~h}$, then a $6 \mathrm{~mm}$ disc was taken from the peripheral zone of mold ( 5 days). The disc was placed in the center of the Petri dish and incubated at $30^{\circ} \mathrm{C}$ for 3 days under aerobic conditions in order to measure the diameter of fungi (Laref et Guessas, 2013). The control was inoculated by the same method without LAB.

\section{Antagonism assays}

\section{Overlay Method}

To detect antifungal activity, overlay assay described by Magnusson et $\boldsymbol{a l}$. (2003) was used with modifications. Isolates were first inoculated in two stripes of $2 \mathrm{~cm}$ on MRS $(15 \mathrm{ml})$ and incubated at $30^{\circ} \mathrm{C}$ for $48 \mathrm{~h}$ under anaerobic conditions. The colonies obtained were then covered with $10 \mathrm{ml}$ of PDA medium (agar $0.9 \%$ ) content $1 \mathrm{ml}$ of monospore suspension $\left(10^{5}\right.$ conidia $\left./ \mathrm{ml}\right)$. The assay without bacterial inoculum served as control. After $72 \mathrm{~h}$ of incubation at $30^{\circ} \mathrm{C}$, the inhibition zones were measured around bacteria streaks, according to the following criteria: (-): Absence of inhibition zone; $(+)$ : Inhibition zone: between 0.1 and $3 \%$ of the surface of the Petri dish; $(++)$ : Inhibition zone: between 3 and $8 \%$ of the surface of the Petri dish; (+++): Inhibition zone: greater than $8 \%$ of the surface of the Petri dish.

\section{Wells method}

This method is based on the principle that antimicrobials substances can diffuse into agar medium. Wells were made using punch on Petri dishes containing PDA medium supplemented with monospore suspension $\left(10^{5}\right.$ conidia/ml $)$. Fresh culture was centrifuged at $4600 \mathrm{x} \mathrm{g}$ for $15 \mathrm{~min}$ and the supernatant was filtered using Millipore filters ( $\varnothing 0.22 \mu \mathrm{m})$ (Millex-GP, Bedford, OH, USA). A volume of 70 to $80 \mu \mathrm{l}$ of filtered supernatant were added to the wells. After $72 \mathrm{~h}$ of incubation at $30^{\circ} \mathrm{C}$, the zones of inhibition were measured.

\section{Antibacterial activity}

To determine the supernatant activity spectrum of the retained LAB, Gram positive and Gram-negative indicator bacteria were tested, well diffusion method described by Tagg and Mac Given (1971) were performed. This indirect method allows the contact between LAB supernatant and the tested strains. LAB was cultivated in MRS broth and incubated for $18 \mathrm{~h}$ at $30^{\circ} \mathrm{C}$. After incubation, the culture was centrifuged at $4600 \mathrm{x}$ g for $15 \mathrm{~min}$ at $4^{\circ} \mathrm{C}$ and the supernatant was stored at $4^{\circ} \mathrm{C}$. indicator strains were inoculated in Mueller-Hinton agar and wells were made with a punch and received $80 \mu \mathrm{l}$ of LAB supernatant. Plates were incubated for $24 \mathrm{~h}$ at $30^{\circ} \mathrm{C}$.

\section{Determination of the inhibitor's nature}

Fresh cultures of LAB were centrifuged at $8450 \mathrm{x}$ g for $15 \mathrm{~min}$ at $4{ }^{\circ} \mathrm{C}$. The supernatant was neutralized with $\mathrm{NaOH} 5 \mathrm{~mol} / \mathrm{L}$ to a $\mathrm{pH}=7$ to eliminate the effect of organic acids. The proteolytic enzymes: trypsin (Sigma-Aldrich, Germany), pepsin (Sigma-Aldrich, Germany) and chymotrypsin (Sigma-Aldrich, Germany) were used to determine the nature of the inhibitory substances. The thermal sensitivity of substances was tested by heating at $80^{\circ} \mathrm{C}$ for $30 \mathrm{~min}$. These substances were tested using the method of Tagg and McGiven (1971).

\section{Supernatant concentration}

The isolates which showed strong inhibitory activity were grown on MRS broth for $48 \mathrm{~h}$ at $30^{\circ} \mathrm{C}$, then centrifuged at $8450 \mathrm{x} \mathrm{g}$ for $15 \mathrm{~min}$ at $4^{\circ} \mathrm{C} .50 \mathrm{ml}$ of the supernatant obtained was added to an equal volume of absolute ethanol and then placed in a separating funnel for 2 days in order to separate the aqueous phase from the organic phase and the latter phase was collected. The solvent removal and the organic phase concentration were performed using rotary evaporator system (Büchi Rotavapor R-114, Büchi, Switzerland) at a temperature of $60^{\circ} \mathrm{C}$. The dry residue was collected and redissolved in $2 \mathrm{ml}$ of phosphate buffer $\left(\mathrm{Na}_{2} \mathrm{HPO}_{4}\right.$ and $\mathrm{NaH}_{2} \mathrm{PO}_{4}, 2 \mathrm{mM}$ at $\left.\mathrm{pH} 7\right)$.

\section{RESULTS AND DISCUSSION}

\section{Isolation and selection of $\mathrm{LAB}$}

A total of 264 isolates were obtained. The initial phenotypic analysis of all isolates was distributed into 2 groups that were Gram (+), catalase (-) and nonspore forming. The first group represented rod forms 80 isolates $(30.30 \%)$, the second group was cocci represented by 166 isolates (62.88\%). A proportion of 19 isolates $(7.2 \%)$ did not possess characters of LAB.

The cells association mode varied from one isolate to another. Isolates that had rod form, $\operatorname{Gram}^{(+)}$catalase $^{(-)}$were chosen for the realization of this study.

\section{Selection of antagonist strains by confrontation method}

The confrontation method described above was used to determine the ability of the selected LAB isolates to inhibit mycelial growth. All of rods isolates were screened against three indicator molds: Penicillium sp., A. fumigatus and A. niger. This test revealed the presence of inhibitory activity for some isolates. A remarkable antagonistic activity was observed toward Penicillium sp. and varied against the other indicator strains. Among these, 14 isolates: Lma1, Lma2, Lma3 Lma4, Lma5, Lma6, Lma7, Lma8, Lma9, Lma10, Lma11, Lma12, Lma13 and Lma14 that process a considerable antifungal activity.

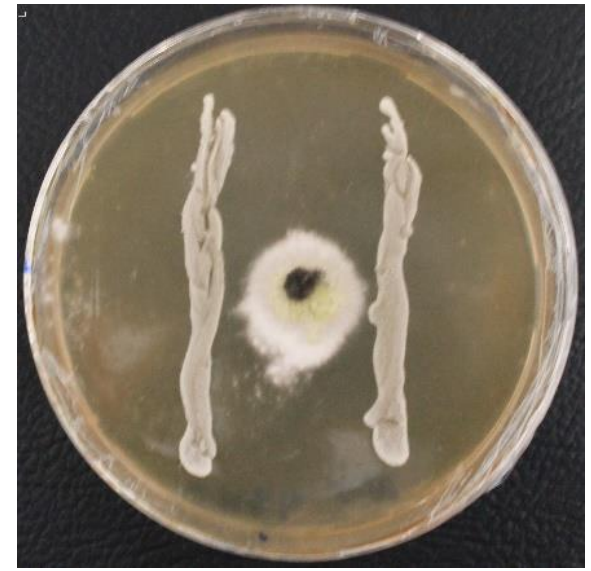

Figure 1 Moderate inhibition by Lactobacillus rhamnosus (Lma1) agains Aspergillus niger using the confrontation method.

Results obtained by the confrontation method illustrated the ability of Lactobacillus ssp. isolates to inhibit A. niger, A. fumigatus and Penicillium sp. 
The fourteen selected isolates showed an inhibitory effect on the three fungal indicators. These lactobacilli were selected according to their antifungal abilities in tests carried out by the confrontation method. The isolates could affect the mycelial growth with various degrees of inhibition for each isolate and also for each indicator strain. In addition, we recorded that $74 \%$ of the isolates showed a high inhibition rate to Penicillium. It has been noted that the strain Lma3 showed antifungal efficacity by strong inhibition against the three molds. These results are similar to the results cited by Fhoula et al. (2013) for LAB isolated from rhizosphere of olive trees and desert truffles on Botrytis cinerea, Penicillium expansum, Verticillium dahliae, and Aspergillus niger. The production of antifungal compounds depends on the selected strain, the growth conditions, and the interactions between fungal and bacterial metabolites (Laref et al., 2013).

Table 1 Carbohydrates fermentation of Lactobacillus isolates obtained by API 50 CHL analyses

\begin{tabular}{llllllllllllllllll} 
strains & Lma5 & Lma11 & Lma3 & Lma1 & Lma10 & Lma7 & Lma9 & Lma2 & Lma4 & Lma6 & Lma8 & Lma13 & Lma12 & Lma14 \\
\hline Tests & & & & & & &
\end{tabular}

\begin{tabular}{|c|c|c|c|c|c|c|c|c|c|c|c|c|c|c|}
\hline W & - & - & - & - & - & - & - & - & - & - & - & - & - & - \\
\hline GLY & - & - & - & - & + & - & - & - & - & - & - & - & - & - \\
\hline ERY & - & - & - & - & - & - & - & - & - & - & - & - & - & - \\
\hline DARA & - & - & - & + & - & - & - & - & - & - & - & - & - & - \\
\hline LARA & - & - & + & - & - & - & - & + & + & + & + & + & + & + \\
\hline RIB & + & + & + & + & + & + & + & + & + & + & + & + & + & + \\
\hline DXYL & - & - & - & - & - & - & - & - & + & - & + & - & - & - \\
\hline LXYL & - & - & - & - & - & - & - & - & - & - & - & - & - & - \\
\hline ADO & - & - & - & - & - & - & - & - & - & - & - & - & - & - \\
\hline MDX & - & - & - & - & - & - & - & - & - & - & - & - & - & - \\
\hline GAL & + & + & + & + & + & + & + & + & + & + & + & + & + & + \\
\hline GLU & + & + & + & + & + & + & + & + & + & + & + & + & + & + \\
\hline FRU & + & + & + & + & + & + & + & + & + & + & + & + & + & + \\
\hline MNE & + & + & + & + & + & + & + & + & + & + & + & + & + & + \\
\hline SBE & - & + & - & + & + & + & + & - & - & - & - & - & - & - \\
\hline RHA & - & - & - & + & - & - & - & - & + & - & - & - & - & - \\
\hline DUL & - & - & - & - & - & - & - & - & - & - & - & - & - & - \\
\hline INO & - & + & - & - & - & - & - & - & - & - & - & - & - & - \\
\hline MAN & + & + & + & + & + & + & + & + & + & + & + & + & + & + \\
\hline SOR & + & + & - & + & + & + & + & + & + & + & + & + & + & + \\
\hline MDM & - & - & - & - & - & - & - & - & - & + & - & + & + & - \\
\hline MDG & - & - & - & + & - & - & - & - & - & - & - & - & - & - \\
\hline NAG & + & + & + & + & + & + & + & + & + & + & + & + & + & + \\
\hline AMY & + & + & + & + & + & + & - & + & + & + & + & + & + & + \\
\hline ARB & + & + & + & + & + & + & + & + & + & + & + & + & + & + \\
\hline ESC & + & + & + & + & + & + & + & + & + & + & + & + & + & + \\
\hline SAL & + & + & + & + & + & + & + & + & + & + & + & + & + & + \\
\hline CEL & + & + & + & + & + & + & + & + & + & + & + & + & + & + \\
\hline MAL & + & + & + & + & + & + & + & + & + & + & + & + & + & + \\
\hline LAC & + & + & - & + & + & + & + & + & + & + & + & + & + & + \\
\hline MEL & - & - & + & - & - & - & - & + & + & + & + & + & + & + \\
\hline SAC & + & + & + & - & + & + & + & + & + & + & + & + & + & + \\
\hline TRE & + & + & + & + & + & + & + & + & + & + & + & + & + & + \\
\hline INU & - & + & - & - & - & - & - & - & - & - & - & - & - & - \\
\hline MLZ & + & + & - & + & + & + & + & + & + & + & + & + & + & + \\
\hline RAF & - & - & - & - & - & - & - & + & - & + & + & + & + & + \\
\hline AMD & - & + & - & - & - & - & - & - & - & - & - & - & - & - \\
\hline GLYG & - & - & - & - & - & - & - & - & - & - & + & - & - & - \\
\hline XLT & - & - & - & - & - & - & - & - & - & - & - & - & - & - \\
\hline GEN & - & + & + & + & + & + & + & + & + & + & + & + & + & + \\
\hline TUR & + & + & - & + & - & + & - & + & + & + & + & + & + & + \\
\hline LYX & - & - & - & - & - & - & - & - & - & - & - & - & - & - \\
\hline TAG & + & + & - & + & + & + & + & - & + & - & + & - & - & - \\
\hline DFUC & - & - & - & - & - & - & - & - & - & - & - & - & - & - \\
\hline LFUC & - & - & - & + & + & - & - & - & - & - & - & - & - & - \\
\hline DARL & - & - & - & - & - & - & - & - & - & - & - & - & - & - \\
\hline LARL & - & + & - & - & - & - & - & - & - & - & - & - & - & - \\
\hline GNT & + & + & + & - & + & + & + & + & - & + & + & + & + & + \\
\hline $2 \mathrm{KG}$ & - & - & - & - & - & - & - & - & - & - & - & - & - & - \\
\hline $5 \mathrm{KG}$ & - & - & - & - & - & - & - & - & - & - & - & - & - & - \\
\hline
\end{tabular}

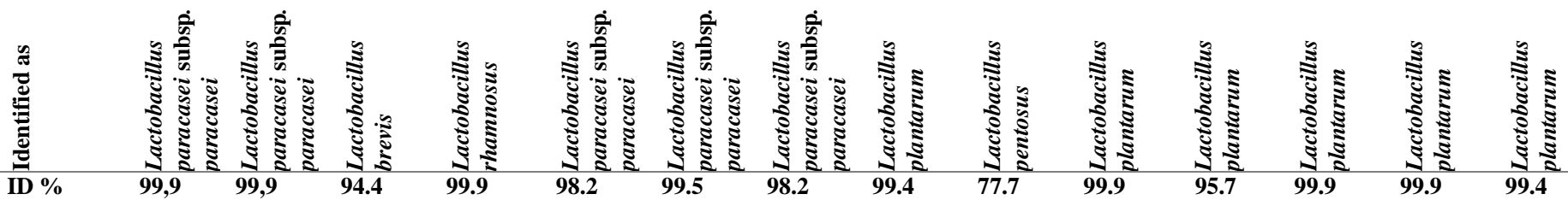

Legend: W: Witness, GLY: Glycérol, ERY: Erythritol, DARA: D- Arabinose, LARA: L- Arabinose, RIB: D- Ribose, DXYL: D- Xylose, LXYL: L- Xylose, ADO: D- Adonitol, MDX Méthyl-D-Xylopyranoside, GAL: D- Galactose GLU: D- Glucose, FRU: D- Fructose, MNE: D- Mannose, SBE: L- Sorbose, RHA: L- Rhamnose, DUL: Dulcitol, INO: Inositol, MAN: DMannitol, SOR: D- Sorbitol, MDM: Méthyl- $\square$ D-Mannopyranoside, MDG: Méthyl- $\square$ D-Glucopyranoside, NAG:N AcétylGlucosamine, AMY: Amygdaline, ARB:Arbutine, ESC:Esculin iron citrate SAL: Salicine, CEL : D- Celiobiose, MAL: D- Maltose, LAC :D- Lactose, MEL: D- Melibiose, SAC: D-Saccharose, TRE: D- Trehalose, INU : Inuline, MLZ : D- Mélézitose, RAF : D- Raffinose, AMD : Amidon, GLYG : Glycogène, XLT : Xylitol, GEN: Gentiobiose, TUR: D-Turanose, LYX: D- Lyxose, TAG: D- Tagatose, DFUC: D- Frucose, LFUC: L-Frucose, DARL: D- Arabitol, LARL: L-Arabitol, GNT: Potassium Gluconate, 2KG: Potassium 2-cétogluconate, 5KG: Potassium 5-cétogluconate 


\section{Isolates identification}

\section{Genus level identification}

Isolates were classified as belonging to the genus Lactobacillus. All isolates were able to grow at $15^{\circ} \mathrm{C}, 2 \%$, and $4 \% \mathrm{NaCl}$. They were grouped according to $\mathrm{CO}_{2}$ production from glucose, gluconate and $\mathrm{NH}_{3}$ production from arginine. Gas production $\left(\mathrm{CO}_{2}\right)$ from glucose, was negative for the 14 isolates. Whereas, in gas production from gluconate all isolates produce $\mathrm{CO}_{2}$. These results show that all isolates are optional heterofermentative. The growth at $45^{\circ} \mathrm{C}$ was observed in 9 isolates. Only one isolate Lma11 that can hydrolyze arginine.

After performed morphological characters and growth at different temperature $\left(15^{\circ} \mathrm{C}, 45^{\circ} \mathrm{C}\right)$, fermentation type (from glucose and gluconate), arginine hydrolysis and ribose fermentation (14 isolates ferment ribose), following the recommendations of Carr et al. (2002), Axelsson (2004) and Hammes and Hertel (2006), we can conclude that the fourteen isolates belonging to the genus Lactobacillus. All isolates are classified in Group II (Streptobacteria) and are optional heterofermentative.

Table 2 Results of the fermentation type (glucose/Gluconate), arginine dehydrogenase activity, ribose fermentation, growth in $\mathrm{NaCl}$ and growth temperatures.

\begin{tabular}{|c|c|c|c|c|c|c|c|c|}
\hline Strains & $\mathrm{CO}_{2}$ from Glucose & $\mathrm{CO}_{2}$ from gluconate & ribose & $2 \% \mathrm{NaCl}$ & $4 \% \mathrm{NaCl}$ & ADH & $15^{\circ} \mathrm{C}$ & $45^{\circ} \mathrm{C}$ \\
\hline Lma1 & 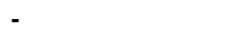 & + & + & + & + & - & + & - \\
\hline Lma2 & - & + & + & + & + & + & + & + \\
\hline Lma3 & - & + & + & + & + & - & + & + \\
\hline Lma4 & - & + & + & + & + & - & + & - \\
\hline Lma5 & - & + & + & + & + & - & + & + \\
\hline Lma6 & - & + & + & + & + & - & + & + \\
\hline Lma7 & - & + & + & + & + & - & + & + \\
\hline Lma8 & - & + & + & + & + & - & + & - \\
\hline Lma9 & - & + & + & + & + & - & + & - \\
\hline Lma10 & - & + & + & + & + & - & + & + \\
\hline Lma11 & - & + & + & + & + & - & + & + \\
\hline Lma12 & - & + & + & + & + & - & + & + \\
\hline Lma13 & - & + & + & + & + & - & + & + \\
\hline Lma14 & - & + & + & + & + & - & + & - \\
\hline
\end{tabular}

Species level identification

The results of carbohydrates fermentation on the API gallery $50 \mathrm{CHL}$, were used to identify species. Based on these results, and following instructions of Carr et al. (2002), Axelsson (2004) and Hammes and Hertel (2006), we classified strains: Lma14, Lma12, Lma13, Lma6, Lma8, Lma2 belong to the species $L b$. plantarum. The Lma5, Lma11, Lma10, Lma7, Lma9 strains belong to the species Lb. paracasei subsp. paracasei. The strain Lma3 belongs to the species Lactobacillus brevis. The strains Lma1 and Lma4 were assigned to the species $L b$. rhamnosus and $L b$. pentosus respectively. Study realized by Khedid et $a l$. (2009) on camel's milk microflora shows that $L b$. plantarum, $L b$. paracasei, $L b$. brevis are the dominant species. Our study reveals another species $L b$. rhamnosus and $L b$. pentosus which have an antifungal activity.

\section{Overlay assay method}

The fourteen (14) Lactobacillus showed an inhibitory activity against the 03 fungi indicator. Overlay assay test revealed also a varied degree of activity against conidia. This remarkable activity differs from one LAB isolate to another and also from a fungal strain to another. All selected isolates (92\%) showed a moderate (++) to strong (+++) antifungal effect on the conidia of A. fumigatus and Penicillium sp. A. niger is the most resistant with low inhibitory activity $(+)$ to moderate $(++)$. The lower antifungal activity against the 3 fungi was recorded for $L b$. plantarum (Lma8), this LAB could not inhibit spore germination of $A$. niger. However, the strain Lb. rhamnosus (Lma1) is the most effective antagonist strain against Penicillium sp., A. fumigatus and A. niger (Figure 2).

Seven (07) LAB isolates showed weak antifungal activity (+) against $A$. niger five (05) isolates showed a moderate activity $(++)$. Our results showed that LAB isolates have a weak to moderate antifungal activity against $A$. niger. For $A$. fumigatus, $21 \%$ of the LAB isolates showed a strong antifungal activity (+++), the rest of the isolates showed moderate activity, with an isolate that showed low activity against this strain. The strong antifungal activity observed (+++) was against Penicillium sp. with $78.57 \%$.

Works of Ström et al. (2002), Magnusson et al. (2003), Rouse et al. (2008), Laref et $\boldsymbol{a l}$. (2013) and Belkacem-Hanfi et $\boldsymbol{a l}$. (2014) confirmed the antifungal activity of lactobacilli on conidia germination of Aspergillus ssp. and Penicillium sp.
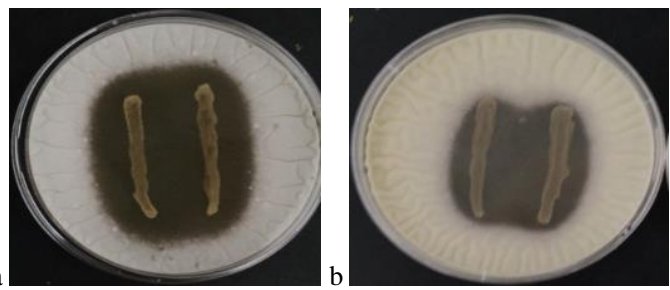

Figure 2 Antifungal activity of Lactobacillus rhamnosus (Lma1) using the overlay technique. (a) Penicillium sp. (b) A. fumigatus.

The retained Lactobacillus spp. isolates were able to inhibit the mycelia growth and the conidia germination, this later were more affected than the mycelia. This result is similar to those cited by Laref and Guessas (2013).

Antifungal activity of $\mathrm{Lb}$. plantarum are reported against Colletotrichum gloeosporioides (Elmabrok et al., 2013), Aspergillus flavus and Penicillium expansum (Cortés-Zavaleta et al., 2014) and Penicillium roqueforti (Yan et al., 2017). The antifungal activity is also described for $L b$. paracasei toward Aspergillus flavus, Aspergillus niger and Penicillium glaucum (Miao et al., 2014), Penicillium sp. (Aunsbjerg et al., 2015) and Aspergillus (Inglin et al., 2015). Studies carried out by Coman et al. (2014), Delavenne et al. (2015) and Inglin et al. (2015) demonstrate that Lb. rhamnosus possess an antifungal activity against Aspergillus, Penicillium, Candida, Rhodotorula, Kluyveromyce, Yarrowia, Botrytis and Colletotrichum. Approved antifungal activity has been noted for Lb. pentosus toward Candida albicans (Crowley et al., 2013), Geotrichum, Alternaria, Fusarium, Aspergillus and Penicillium (Lipińska et al., 2017). The antifungal action of Lactobacillus brevis is cited by the authors Tropcheva et al. (2014), Arasu et al. (2015) and Axel et al. (2016).

No antifungal activity was recorded by the free-cell supernatant for all isolates, the same results were obtained by Schwenninger and Meile (2004) and Laref and Guessas (2013).

Table 3 Antifungal activity tested by the overlay method

$\begin{array}{ll}\text { Strains } & \text { Isolates code } \\ \text { Lactobacillus rhamnosus } & \mathrm{Lma} 1 \\ \text { Lactobacillus plantarum } & \mathrm{Lma} 2 \\ \text { Lactobacillus brevis } & \mathrm{Lma} 3 \\ \text { Lactobacillus pentosus } & \mathrm{Lma} 4 \\ \text { Lactobacillus paracasei subsp. paracasei } & \mathrm{Lma} 5 \\ \text { Lactobacillus plantarum } & \mathrm{Lma} 6 \\ \text { Lactobacillus paracasei subsp. paracasei } & \mathrm{Lma} 7 \\ \text { Lactobacillus plantarum } & \mathrm{Lma} 8 \\ \text { Lactobacillus paracasei } \text { subsp. paracasei } & \mathrm{Lma} 9 \\ \text { Lactobacillus paracasei subsp. paracasei } & \mathrm{Lma} 10 \\ \text { Lactobacillus paracasei } \text { subsp. paracasei } & \mathrm{Lma} 11 \\ \text { Lactobacillus plantarum } & \mathrm{Lma} 12 \\ \text { Lactobacillus plantarum } & \mathrm{Lma} 13 \\ \text { Lactobacillus plantarum } & \mathrm{Lma} 14\end{array}$

A. niger
++
ND
++
+
++
+
++
-
+
++
+
+
+
+

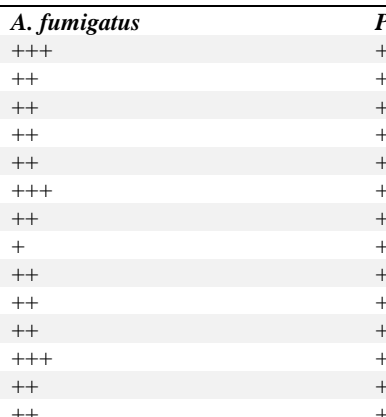

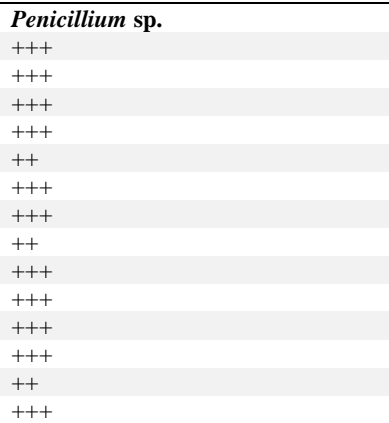

Legend: (-): Absence of inhibition zone; (+): Inhibition zone between 0.1 and $3 \%$ of the surface of the Petri dish (low); (++): Inhibition area between 3 and $8 \%$ of the surface of the Petri dish (moderate); (+++): Inhibition area greater than $8 \%$ of the surface of the Petri dish. (Strong); (ND): not determined 


\section{Antibacterial activity}

In addition to the antifungal activity, LAB isolates revealed also a high antibacterial activity spectrum, the results showed the effect of unbuffered supernatant on the growth of E. coli ATCC 25922, S. aureus ATCC 25923, L ivanovii ATCC 19119 and P. aeruginosa. The results showed that 14 strains $(100 \%)$ had an inhibition against $P$. aeruginosa, E. coli and $S$. aureus, 05 of these isolates $(36 \%)$ showed a strong inhibitory activity. However, $(85.71 \%)$ affect $L$. ivanovii. This activity has been recorded for $L b$. brevis (Lma3) isolate, $L b$. rhamnosus (Lma1), Lb. plantarum (Lma2), Lb. plantarum (Lma8) and $L b$. paracasei subsp. paracasei (Lma9). Six isolates (43\%) showed strong inhibitory activity against E. coli. 06 strains affect L. ivanovii ATCC 19119 with moderate activity. Six (06) lactobacilli also showed a strong inhibitory activity against $P$. aeruginosa (diameter varied between 17 to $22 \mathrm{~mm}$ ). Lactobacilli's Isolates showed a wide range of antibacterial activity on both of Gram (-) and Gram positive (+) indicator: E. coli ATCC 25922, P. aeruginosa, L. ivanovii ATCC 19119 and $S$. aureus ATCC 25923. Inhibition of E. coli by Lactobacillus strains has already been described (Todorov et al., 2004; Karthikeyan and Santosh, 2009). Todorov et $a l$. in 2004 and Karthikeyan \& Santosh in 2009 had recorded the inhibition of the strain of P. aeruginosa by Lactobacillus ssp. The anti-Listerial activity of Lactobacillus has been described by Ouwehand and Vesterlund (2004). In 2008 Mami and collaborators mention that Lactobacillus strains isolated from raw goat milk inhibit $S$. aureus strains.

Table 4 Antibacterial inhibition diameter $(\mathrm{mm})$ of LAB strains on bacterial indicator

Lactic acid bacteria

Strains test

S. aureus

E. coli

P. aeruginosa

L. ivanovii

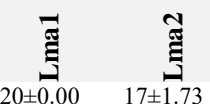

$23 \pm 0.00$

$21 \pm 0.00$

$12 \pm 1.00 \quad 13 \pm 0.00$
壱

$20 \pm 1.73$

$20 \pm 2.64$

$19 \pm 0.00$

$14 \pm 1.00$

$15 \pm 1.00$

$16 \pm 1.00$

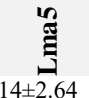

$15 \pm 1.00$

$16 \pm 1.00$

$17 \pm 0.00$

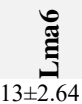

$18 \pm 1.00$

$13 \pm 1.00$

$13 \pm 1.00$
롫

$16 \pm 1.00$

है

$21 \pm 1.00$

$\underset{17 \pm 1.00}{\text { 코ำ }}$

ฮี

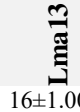

ีㅗㄹ

$14 \pm 1.00 \quad 17 \pm 1.00$

$16 \pm 0.00 \quad 21 \pm 1.00$

$14 \pm 1.00$

$18 \pm 0.00$

$12 \pm 2.64$

$19 \pm 1.00$

$5 \pm 0.00$

$18 \pm 1.00$

$22 \pm 1.00$

$15 \pm 0.00$

$12 \pm 0.00$

$13 \pm 1.00$

$14 \pm 1.00$

$16 \pm 1.73$

$08 \pm 0.00 \quad 13 \pm 1.00$

$17 \pm 1.00$

Table 5 Inhibition diameter $(\mathrm{mm})$ of the neutralized LAB free-cell supernatant against $P$. aeruginosa.

\begin{tabular}{|c|c|c|c|c|c|c|c|c|c|c|c|c|c|c|}
\hline & Lma6 & Lma4 & Lma13 & Lma8 & Lma14 & Lma5 & Lma7 & Lma2 & Lma11 & Lma3 & Lma1 & Lma12 & Lma10 & Lma9 \\
\hline P. aeruginosa & $17 \pm 1.00$ & $14 \pm 1.73$ & $12 \pm 0.00$ & $20 \pm 1.00$ & $19 \pm 1.00$ & $18 \pm 1.00$ & $26 \pm 3.60$ & $27 \pm 1.73$ & $20 \pm 1.00$ & $21 \pm 0.00$ & $19 \pm 1.00$ & $24 \pm 1.00$ & $18 \pm 1.00$ & $23 \pm 0.00$ \\
\hline
\end{tabular}

\section{The concentrated filtrate}

The free-cell concentrated supernatant of Lb. brevis (Lma3) was able to inhibit both of all fungal and bacterial strains. Penicillium sp. is the most sensitive mold with $18 \mathrm{~mm}$ zone of inhibition, followed by A. fumigatus $(16 \mathrm{~mm})$. A. niger showed resistance to concentrated filtrate as the inhibition zone did not exceed 12 $\mathrm{mm}$. Concentered free-cell supernatant affect also E. coli, L. ivanovii, $P$. aeruginosa and $S$. aureus with diameters of inhibitions between 16 to $22 \mathrm{~mm}$. It has been noted that $S$. aureus was the most sensitive against the free-cell concentrated supernatant. Wang and collaborators in 2012 showed the effect of the concentrate filtrate of $L b$. plantarum against $P$. citrinum and $P$. digitatum. Saraniya and Jeevaratnam (2014) showed that S. aureus MTCC 737 was inhibited by the concentrate supernatant (10 times) of $\mathrm{Lb}$. pentosus. The antimicrobial effect of the concentrate free-cell supernatant $L b$. plantarum on $P$. aeruginosa and E. coli has been also reported by Smaoui et al. (2010).

\section{Determination of inhibitor nature}

Neutralizing $\mathrm{pH}$, treatment with proteolytic enzymes and heating of free-cell supernatant revealed that no inhibitory effect on A. niger, A. fumigatus, Penicillium sp., S. aureus ATCC 25923, E. coli ATCC 25922 and L. ivanovii ATCC 19119. However, this inhibitory effect persisted on the $P$. aeruginosa strain. Laref et al. (2013) motioned this persistence of inhibitory effect on this strain.

Neutralization of free-cell supernatant can eliminate the activity of antifunga compounds. Magnusson and Schnurer (2001) described that the antifungal substance is activated in low $\mathrm{pH}$, this peptide was stable at $\mathrm{pH}$ values between 3.0 and 4.5 but decreased between 4.5 and 6.0., In addition, the study of Rouse et van Sinderen (2008) had confirmed that treatment of the concentrated supernatant of $\mathrm{Lb}$. plantarum with proteinase $\mathrm{K}$ suppress the antifungal activity. Miescher Schwenninger et al. (2005) reported that heating for $10 \mathrm{~min}$ at $100^{\circ} \mathrm{C}$ of the supernatant of $L b$. paracasei subsp. paracasei isolates don't affect the antifungal activity. The antifungal activity of lactobacilli is less well characterized, but organic acids, as still uncharacterized proteinaceous compounds, and cyclic dipeptides can inhibit the growth of some fungi (Rouse et van Sinderen, 2008). Organic acids produced by Lactobacillus ssp., such as 3hydroxy fatty acids and phenyllactic acid, have been recently described for their inhibitory effect on the growth of some fungal (Lee et al., 2016; Russo et $\boldsymbol{a l}$., 2017; Lipińska et al., 2017; Dinev et al., 2017). Lb. rhamnosus been reported to inhibit the growth of many spoilage and toxigenic fungi including species in the genera Aspergillus and Penicillium (Plockova et al., 2001). Iglesias et al. (2018) cited that the antifungal activity of Lb. rhamnosus GG can be related to emissions of many volatiles compounds. Recently, number of antifungal metabolites: Cyclo-(Leu-Pro), 2,6-diphenyl -piperidine, and 5,10-diethoxy-2,3,7, 8tetrahydro-1H, 6H-dipyrrolo[1,2-a;10,20-d]pyrazine, Phenyllactic acid, 3Propanoic acid, Sinapic acid, 2-Deoxycytidine, Cyclo (L-His-L Pro), Cyclo (LTyr-L Pro), Phenylpyruvic acid, cis-Caftaric acid, Protocatechuicacidhexoside, Caffeic acid derivative, Hydroxycinnamic acid derivative, Quercetinpentoside, Quinic acid derivative, Caffeoylhexose-deoxyhexoside, 3,5-Di-O-caffeoylquinic acid are isolated from Lactobacillus species (Li et al., 2012; Yépez et al., 2017).

Table 6 Inhibition Diameter (mm) of concentered free-cell supernatant of Lactobacillus brevis (Lma3) compared with the ethanol against fungal and bacterial indicator

\begin{tabular}{|c|c|c|c|c|c|c|c|}
\hline & P. aeruginosa & S. aureus & E. coli & L. ivanovii & A. niger & A. fumigatus & Penicillium sp \\
\hline Concentered supernatant & $19 \pm 1.00$ & $22 \pm 1.00$ & $16 \pm 1.00$ & $18 \pm 1.00$ & $12 \pm 1.00$ & $16 \pm 1.00$ & $18 \pm 1.00$ \\
\hline Ethanol & $13 \pm 1.00$ & $14 \pm 1.00$ & $13 \pm 1.00$ & $15 \pm 1.00$ & $11 \pm 1.00$ & $12 \pm 1.00$ & $13 \pm 1.00$ \\
\hline Difference & 6 & 8 & 3 & 3 & 1 & 4 & 5 \\
\hline
\end{tabular}

\section{CONCLUSION}

This paper reported the isolation and identification of LAB from Algerian camel's milk. The results showed a high rate of antifungal activity, indicating that camel's milk may be source for the selection of new LAB with important technological potential, which are useful for the biocontrol of food, plant, fungi and pathogenic bacteria. These antifungal strains LAB have potential characters to be used in food preservation to inhibit conidia germination and mycelia growth of spoilage fungi. Further investigations to elucidate the nature of inhibiting compounds should be considered.

\section{REFERENCES}

Arasu, M. V., Al-Dhabi, N. A., Rejiniemon, T. S., Lee, K. D., Huxley, V., Kim, D. H., Choi, K. C. 2015. Identification and characterization of Lactobacillus brevis P68 with antifungal, antioxidant and probiotic functional properties. Indian journal of microbiology, 55(1), 19-28. https://dx.doi.org/10.1007/s12088014-0495-3

Ashley-Martin, J., VanLeeuwen, J., Cribb, A., Andreou, P., \& Guernsey, J. R. 2012. Breast cancer risk, fungicide exposure and $\mathrm{CYP}_{\mathrm{A}} 1^{*}$ 2A geneenvironment interactions in a province-wide case control study in Prince Edward Island, Canada. International journal of environmental research and public health, 9(5), 1846-1858. https://dx.doi.org/10.3390/ijerph9051846

Aunsbjerg, S. D., Honoré, A. H., Marcussen, J., Ebrahimi, P., Vogensen, F. K., Benfeldt, C., . . . Knøchel, S. 2015. Contribution of volatiles to the antifungal effect of Lactobacillus paracasei in defined medium and yogurt. International journal of food microbiology, 194, 46-53. https://dx.doi.org/10.1016/j.ijfoodmicro.2014.11.007

Axel, C., Brosnan, B., Zannini, E., Peyer, L. C., Furey, A., Coffey, A., \& Arendt, E. K. 2016. Antifungal activities of three different Lactobacillus species and their 
production of antifungal carboxylic acids in wheat sourdough. Applied microbiology and biotechnology, 100(4), 1701-1711. https://dx.doi.org/10.1007/s00253-015-7051-x

Axelsson, L. T. 2004. Lactic Acid Bacteria: Classification and Physiology. In A v. W. Lactic Acid Bacteria -Microbiology and functional aspects. Salminen S., Ouwehand A. (Ed.), (pp. 1-66.): Marcel Dekker, Inc. https://dx.doi.org/10.1201/9780824752033.ch1

Belkacem-Hanfi, N., Fhoula, I., Semmar, N., Guesmi, A., Perraud-Gaime, I., Ouzari, H.-I., Roussos, S. 2014. Lactic acid bacteria against post-harvest moulds and ochratoxin A isolated from stored wheat. Biological Control, 76, 52-59. https://dx.doi.org/10.1016/j.biocontrol.2014.05.001

Bennett, J. W., \& Klich, M. 2003. Mycotoxins. Clinical Microbiology Reviews, 16(3), 497-516. https://doi.org/10.1128/cmr.16.3.497-516.2003

Carr, F. J., Chill, D., \& Maida, N. 2002. The lactic acid bacteria: a literature survey. Critical reviews in microbiology, 28(4), 281-370. https://dx.doi.org/10.1080/1040-840291046759

Coman, M., Verdenelli, M., Cecchini, C., Silvi, S., Orpianesi, C., Boyko, N., \& Cresci, A. 2014. In vitro evaluation of antimicrobial activity of Lactobacillus rhamnosus IMC 501®, Lactobacillus paracasei IMC 502® and SYNBIO ${ }^{\circledR}$ against pathogens. Journal of Applied Microbiology, 117(2), 518-527. https://dx.doi.org/10.1111/jam.12544

Cortés-Zavaleta, O., López-Malo, A., Hernández-Mendoza, A., \& García, H. 2014. Antifungal activity of lactobacilli and its relationship with 3-phenyllactic acid production. International journal of food microbiology, 173, 30-35. https://dx.doi.org/10.1016/j.ijfoodmicro.2013.12.016

Crowley, S., Mahony, J., \& van Sinderen, D. 2013. Current perspectives on antifungal lactic acid bacteria as natural bio-preservatives. Trends in Food $\begin{array}{llll}\text { Science } \quad \text { \& } & \text { Technology, } & \text { 33(2), } & \text { 93-109. }\end{array}$ https://dx.doi.org/10.1016/j.tifs.2013.07.004

Dalié, D. K. D., Deschamps, A. M., \& Richard-Forget, F. 2010. Lactic acid bacteria - Potential for control of mould growth and mycotoxins: A review. Food Control, 21(4), 370-380. http://dx.doi.org/10.1016/j.foodcont.2009.07.011

Delavenne, E., Cliquet, S., Trunet, C., Barbier, G., Mounier, J., \& Le Blay, G. 2015. Characterization of the antifungal activity of Lactobacillus harbinensis $\mathrm{K}$ V9. $3.1 \mathrm{~Np}$ and Lactobacillus rhamnosus K. C8. $3.1 \mathrm{I}$ in yogurt. Food Microbiology, 45, 10-17. https://dx.doi.org/10.1016/j.fm.2014.04.017

Dinev, T., Beev, G., Tzanova, M., Denev, S., Dermendzhieva, D., \& Stoyanova, A. 2017. Antimicrobial activity of Lactobacillus plantarum against pathogenic and food spoilage microorganisms: A review. Bulg. J. Vet. Med.

Elmabrok, A., Hassan, Z., Hussin, K., \& Mokhtar, A. 2013. Antifungal activity of Lactobacillus plantarum LAB-C5 and LAB-G7 isolated from Malaysian fruits. Fhoula, I., Najjari, A., Turki, Y., Jaballah, S., Boudabous, A., \& Ouzari, H. 2013 Diversity and Antimicrobial Properties of Lactic Acid Bacteria Isolated from Rhizosphere of Olive Trees and Desert Truffles of Tunisia. BioMed Research International, 2013, 14. https://doi.org/10.1155/2013/405708

Hammes, W. P., \& Hertel, C. 2006. The genera Lactobacillus and Carnobacterium The prokaryotes (pp. 320-403): Springer https://dx.doi.org/10.1007/0-387-30744-3_10

Iglesias, M., Echeverría, G., Viñas, I., López, M., \& Abadias, M. 2018 Biopreservation of fresh-cut pear using Lactobacillus rhamnosus GG and effect on quality and volatile compounds. LWT-Food Science and Technology, 87, 581588. https://dx.doi.org/10.1016/j.lwt.2017.09.025

Inglin, R. C., Stevens, M. J. A., Meile, L., Lacroix, C., \& Meile, L. 2015. Highthroughput screening assays for antibacterial and antifungal activities of Lactobacillus species. Journal of Microbiological Methods, 114, 26-29. https://doi.org/10.1016/j.mimet.2015.04.011

Karthikeyan, V., \& Santosh, S. 2009. Isolation and partial characterization of bacteriocin produced from Lactobacillus plantarum. Afr. J. Microbiol. Res, 3(5), 233-239.

Khedid, K., Faid, M., Mokhtari, A., Soulaymani, A., \& Zinedine, A. 2009. Characterization of lactic acid bacteria isolated from the one humped camel milk produced in Morocco. Microbiological research, 164(1), 81-91. https://dx.doi.org/10.1016/j.micres.2006.10.008

Laref, N., \& Guessas, B. 2013. Antifungal activity of newly isolates of lactic acid bacteria. Innovative Romanian Food Biotechnology, 13, 80-88.

Laref, N., Guessas, B., \& Kihal, M. 2013. pH and on Modified MRS Agar by Lactobacillus Strains. Journal of Biological Sciences, 13(2), 94-99. https://dx.doi.org/10.3923/jbs.2013.94.99

Lee, Y. G., Cho, J.-Y., \& Moon, J.-H. 2016. Isolation and antioxidative activity of amino acid derivatives produced by Leuconostoc mesenteroides. Food Science and Biotechnology, 25(1), 329-334. https://dx.doi.org/10.1007/s10068-016-00462

Li, H., Liu, L., Zhang, S., Cui, W., \& Lv, J. 2012. Identification of antifungal compounds produced by Lactobacillus casei AST18. Current microbiology, 65(2), 156-161. https://dx.doi.org/10.1007/s00284-012-0135-2

Lipińska, L., Klewicki, R., Sójka, M., Bonikowski, R., Żyżelewicz, D., Kołodziejczyk, K., \& Klewicka, E. 2017. Antifungal Activity of Lactobacillus pentosus ŁOCK 0979 in the Presence of Polyols and Galactosyl-Polyols. Probiotics and antimicrobial proteins, 1-15. https://dx.doi.org/10.1007/s12602$\underline{017-9344-0}$
Magnusson, J., \& Schnürer, J. 2001. Lactobacillus coryniformis subsp. coryniformis strain $\mathrm{Si3}$ produces a broad-spectrum proteinaceous antifungal compound. Applied and Environmental Microbiology, 67(1), 1-5. https://dx.doi.org/10.1128/AEM.67.1.1-5.2001

Magnusson, J., Ström, K., Roos, S., Sjögren, J., \& Schnürer, J. 2003. Broad and complex antifungal activity among environmental isolates of lactic acid bacteria FEMS Microbiology Letters, 219(1), 129-135. doi:10.1016/s03781097(02)01207-7 https://dx.doi.org/10.1016/S0378-1097(02)01207-7

Mami, A., Henni, J. E., \& Kihal, M. 2008. Antimicrobial activity of Lactobacillus species isolated from Algerian raw goat's milk against Staphylococcus aureus. World J Dairy Food Sci, 3(2), 39-49.

Mathot, A., Kihal, M., Prevost, H., \& Divies, C. 1994. Selective enumeration of Leuconostoc on vancomycin agar media. International Dairy Journal, 4(5), 459469

Miao, J., Guo, H., Ou, Y., Liu, G., Fang, X., Liao, Z., Cao, Y. 2014. Purification and characterization of bacteriocin $\mathrm{F} 1$, a novel bacteriocin produced by Lactobacillus paracasei subsp. tolerans FX-6 from Tibetan kefir, a traditional fermented milk from Tibet, China. Food Control, 42, 48-53. https://dx.doi.org/10.1016/j.foodcont.2014.01.041

Ouwehand, A. C., \& Vesterlund, S. 2004. Antimicrobial components from lactic acid bacteria. food science and technology-new york-marcel dekker-, 139, 375 396. https://dx.doi.org/10.1007/s12393-012-9051-2

Pawlowska, A. M., Zannini, E., Coffey, A., \& Arendt, E. K. 2012. Chapter 5 "Green Preservatives": Combating Fungi in the Food and Feed Industry by Applying Antifungal Lactic Acid Bacteria. In H. Jeyakumar (Ed.), Advances in Food and Nutrition Research (Vol. Volume 66, pp. 217-238): Academic Press. https://dx.doi.org/10.1016/B978-0-12-394597-6.00005-7

Pitt, J. I. 2000. Toxigenic fungi: which are important? Medical Mycology, 38(sup1), 17-22. https://doi.org/10.1080/mmy.38.s1.17.22

Plockova, M., Stiles, J., Chumchalova, J., \& Halfarova, R. 2001. Control of mould growth by Lactobacillus rhamnosus VT1 and Lactobacillus reuteri CCM 3625 on milk agar plates. Czech Journal of Food Sciences, 19(2), 46-50.

Rouse, S., Harnett, D., Vaughan, A., \& Sinderen, D. v. 2008. Lactic acid bacteria with potential to eliminate fungal spoilage in foods. Journal of Applied Microbiology, 104(3), 915-923. https://dx.doi.org/10.1111/j.13652672.2007.03619.x

Rouse, S., \& van Sinderen, D. 2008. Bioprotective potential of lactic acid bacteria in malting and brewing. Journal of food protection, 71(8), 1724-1733. https://dx.doi.org/10.4315/0362-028X-71.8.1724

Russo, P., Arena, M. P., Fiocco, D., Capozzi, V., Drider, D., \& Spano, G. 2017. Lactobacillus plantarum with broad antifungal activity: A promising approach to increase safety and shelf-life of cereal-based products. International journal of food microbiology, 247, 48-54. https://dx.doi.org/10.1016/j.ijfoodmicro.2016.04.027

Saraniya, A., \& Jeevaratnam, K. 2014. Optimization of nutritional and nonnutritional factors involved for production of antimicrobial compounds from Lactobacillus pentosus SJ65 using response surface methodology. Brazilian Journal of Microbiology, 45(1), 81-88. http://dx.doi.org/10.1590/S1517$\underline{83822014000100012}$

Schwenninger, S. M., \& Meile, L. 2004. A mixed culture of Propionibacterium jensenii and Lactobacillus paracasei subsp. paracasei inhibits food spoilage yeasts. Systematic and applied microbiology, 27(2), 229-237. https://dx.doi.org/10.1078/072320204322881853

Smaoui, S., Elleuch, L., Bejar, W., Karray-Rebai, I., Ayadi, I., Jaouadi, B., Mellouli, L. 2010. Inhibition of Fungi and Gram-Negative Bacteria by Bacteriocin BacTN635 Produced by Lactobacillus plantarum sp. TN635. Applied $\begin{array}{lll}\text { Biochemistry and Biotechnology, 162(4), 1132-1146. } & \end{array}$ https://dx.doi.org/10.1007/s12010-009-8821-7

Steyn, P. S. 1995. Mycotoxins, general view, chemistry and structure. Toxicology Letters, 82-83, 843-851 http://dx.doi.org/10.1016/0378-4274(95)03525-7

Ström, K. 2005. Fungal inhibitory lactic acid bacteria: Characterization and application of Lactobacillus plantarum MiLAB 393. (doctorat Doctoral thesis), Swedish University of Agricultural Sciences Uppsala

Ström, K., Sjögren, J., Broberg, A., \& Schnürer, J. 2002. Lactobacillus plantarum MiLAB 393 produces the antifungal cyclic dipeptides cyclo (L-Phe-LPro) and cyclo (L-Phe-trans-4-OH-L-Pro) and 3-phenyllactic acid. Applied and $\begin{array}{llll}\text { Environmental } & \text { Microbiology, } & 68(9), & 4322-4327 .\end{array}$ http://dx.doi.org/10.1128/AEM.68.9.4322-4327.2002

Tagg, J., \& McGiven, A. 1971. Assay system for bacteriocins. Applied microbiology, 21(5), 943.

Thomas, T. 1973. Agar medium for differentiation of Streptococcus cremoris from the other bacteria. NZJ Dairy Sci. Technol, 8, 70-71.

Todorov, S. D., Reenen, C. A. v., \& Dicks, L. M. T. 2004. Optimization of bacteriocin production by Lactobacillus plantarum ST13BR, a strain isolated from barley beer. The Journal of general and applied microbiology, 50(3), 149157. https://dx.doi.org/10.2323/jgam.50.149

Tropcheva, R., Nikolova, D., Evstatieva, Y., \& Danova, S. 2014. Antifungal activity and identification of Lactobacilli, isolated from traditional dairy product "katak". Anaerobe, 28, 78-84. https://dx.doi.org/10.1016/j.anaerobe.2014.05.010 Yan, B., Zhao, J., Fan, D., Tian, F., Zhang, H., \& Chen, W. 2017. Antifungal Activity of Lactobacillus plantarum Against Penicillium roqueforti in Vitro and 
the Preservation Effect on Chinese Steamed Bread. Journal of Food Processing and Preservation, 41(3). https://dx.doi.org/10.1111/jfpp.12969

Yépez, A., Luz, C., Meca, G., Vignolo, G., Mañes, J., \& Aznar, R. 2017.

Biopreservation potential of lactic acid bacteria from Andean fermented food of

vegetal origin Food Control

https://dx.doi.org/10.1016/j.foodcont.2017.03.009 